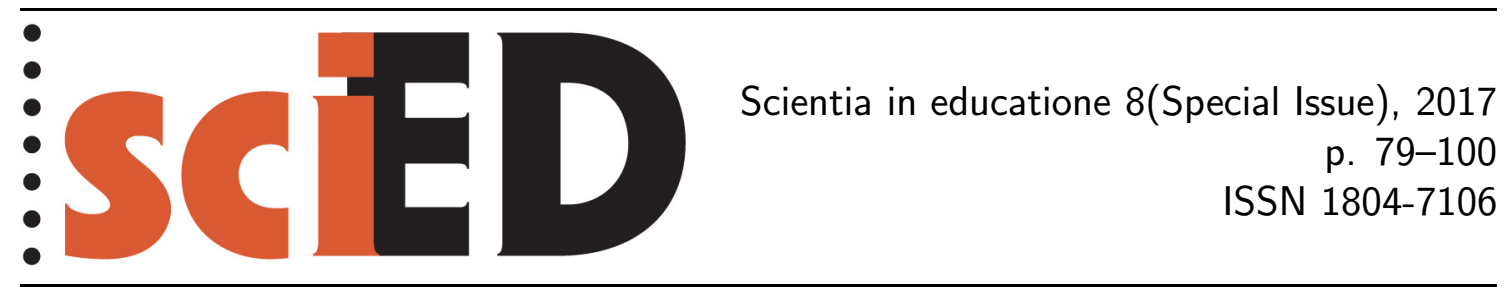

\title{
Active Physics Learning: Making Possible Students' Cognitive Growth, Positive Emotions and Amazing Creativity
}

Josip Sliško

\begin{abstract}
It is now well known that carefully designed sequences of active physics learning support students' comprehension of physical concepts and laws. If only this were its effect, active learning should replace lecture-based teaching and passive students' learning at all educational levels. Fortunately, the impacts of active learning experiences in students are much broader. In this paper I present a few examples of tasks that are suited for engaging students in active learning along with research-based and anecdotal evidence about effects of active physics learning on students' cognitive level, emotions and creativity.
\end{abstract}

Key words: active physics learning, self-regulated learning, cognitive growth, positive emotions, creative thinking, students' demonstrations of weightlessness. 


\section{INTRODUCTION}

Our today's students will live and work in the world of learning organizations and knowledge-based economy that change faster and faster. Life-long learning is their destiny and only possible path towards new employment opportunities and a secure personal and professional future! But the learning is not only a personal need, it is also an economic necessity (Argyris, 1991):

"Any company that aspires to succeed in the tougher business environment of the 1990s must first resolve a basic dilemma: Success in the marketplace increasingly depends on learning, yet most people don't know how to learn.

What's more, those members of the organization that many assume to be the best at learning are, in fact, not very good at it."

Only "knowledge workers", whose role is to transform existing and emerging knowledge into new products and services, can satisfy such a necessity. The number and quality of "knowledge workers" affect the present and the future of institutions and companies (Drucker, 1999):

"The most valuable asset of a 21st-century institution (whether business or nonbusiness) will be its knowledge workers and their productivity.

Knowledge work requires continuous learning on the part of the knowledge worker, but equally continuous teaching on the part of the knowledge worker."

Becoming a "knowledge worker" is not a trivial task. It requires that one dominate many complex skills which can only be learned through adequate learning experiences (Drucker, 2005):

"Knowledge workers must, effectively, be their own chief executive officers. It's up to you to carve out your place, to know when to change course, and to keep yourself engaged and productive during a work life that may span some 50 years. To do those things well, you'll need to cultivate a deep understanding of yourself not only what your strengths and weaknesses are but also how you learn, how you work with others..."

These complex skills, needed by "knowledge workers" and business leaders, are recently called "XXI century skills". Tim Wagner (2008), considers them as "surviving skills" and includes among them:

- Critical thinking and problem solving; Collaboration and leadership;

- Effective oral and written communication; Finding and analyzing information;

- Curiosity and imagination.

Higher-education institutions have a very important social responsibility in education of "knowledge workers", who should be prepared to face, not only today's known problems, but more future unknown problems which will appear in next decades (Jarvis, 2001; Graham, 2002) .

Keeling and Hersh consider that learning, needed by actual knowledge-based economy,

"... requires that students be fully engaged participants in a powerful intellectual, social, and developmental process. That process requires rigorous self-discipline, effort, and commitment; demanding well-trained teachers; an inspiring, motivating, and diverse curriculum; and an intentionally designed, challenging, formative, and supportive learning environment" (Keeling \& Hersh, 2012: p. 20).

Nevertheless, the university teaching, even in the most industrialized countries like the USA, is slow and unprepared to react adequately to these urgent economic needs. Keeling and Hersh made a dramatic diagnosis of that situation: 
"The truth is painful but must be heard: we're not developing the full human and intellectual capacity of today's college students because they're not learning enough and because the learning that does occur is haphazard and of poor quality. Too many of our college graduates are not prepared to think critically and creatively, speak and write cogently and clearly, solve problems, comprehend complex issues, accept responsibility and accountability, take the perspective of others, or meet the expectations of employers. Metaphorically speaking, we are losing our minds." (Keeling \& Hersh, 2012: p. 1).

According to Keeling and Hersch, one of the main causes of this situation is teaching-centered culture of colleges and universities:

"Since teaching is what matters and what is measured, instruction is mostly lecture-driven and learning, to the extent that it occurs, is mostly passive, receptive enterprise. In other words, students should come to class, listen carefully, take good notes, and be grateful." (Keeling \& Hersh, 2012: p. 20).

\section{LECTURE-BASED PHYSICS TEACHING: A PARADIGMATIC EXAMPLE, SOME LEARNING OUTCOMES AND THEIR} CAUSE

The central element of "teaching-centered culture" is lecture-based delivery of the course content. It has its roots in medieval pedagogy, when it was the only possible way of passing knowledge from a teacher to students who lived in a world in which books were very rare and expensive. Times have changed drastically and access to printed and digital books increased dramatically.

Nevertheless, lecture-based teaching, complemented by recitation sessions for solving end-of-chapter problems and cookbook lab activities, is still dominating practice in physics education. Its colorful description was given some times ago (Gautreau \& Novemsky, 1997):

"Stroll down the corridors of a typical college, and glance in some of the classrooms where freshman courses in physics or other technical areas are being taught. Chances are you will see something like the following. Instructors in front of their captive - but rarely captivated - audience are extolling, with various degrees of enthusiasm, the virtues of physics and solving the problems of the week. Seated obediently in uniform rows facing their leader are the "students", vigorously scribbling in attempts to transcribe each utterance and every blackboard marking of the instructor. Eyes glaze as students try to avoid fading off."

A paradigmatic example of this way of teaching, with the highest degree of instructor's enthusiasm, might be a set of physics lectures delivered by MIT professor Walter G. H. Lewin in 1999. With YouTube revolution, their video versions became world - wide popular, attracting millions of viewers. Prof. Lewin loves physics, and enjoys sharing his love, both with students in lecture hall and the readers of his recent book (Lewin, 2012). While in lecture-hall, he talks eloquently and with a touch of gentle humor, draws nice sketches and schemes, writes many formulas and performs eye-catching demonstrations and experiments.

What are students doing during the lecture? They have to divide their attention between listening to the words said, copying into their notebooks what is written on the blackboard and watching what is Prof. Lewin trying to demonstrate. Being so, they are not given any opportunity to participate intellectually, by answering and 
discussing some professor's rhetoric questions (what will happen if I do that?) or formulating their own questions (why did you say that?).

The above description was derived from Prof. Lewin's lecture "Weight, perceived gravity and weightlessness" (Lewin, 1999), which was selected because I recently started to use the topic of weightlessness as a context to explore students creativity (preliminary results will be presented later in the article).

The 50-minute lecture has three main parts, carefully thought out and ordered: (1) concepts' introduction and application; (2) low-teach and high-tech classroom demonstrations of weightlessness; and (3) video presentation of weightlessness inside a plane in free (engines-off) parabolic motion.

The concept of weight is a very controversial one, having at least three different conceptualizations (Galili, 2001). Although Prof. Lewin recognizes it, saying explicitly that the weight is a non-intuitive and tricky "thing", he introduces it straightly (and unorthodoxly) as the upward force a scale exerts on the body being weighted (Figure 1). Such a definition strongly contradicts both students' previous intuitive ideas about, and learning experiences with the weight concept, but no opportunity is given to them to reconsider their ideas and experiences. Instead, a rapid exposition of a few applications of the weight concept is presented. Some of results, very likely paradoxical to students (bodies of different masses, connected by a string over a pulley, in an accelerated motion have the same weight), were elaborated and commented as being almost self-evident.
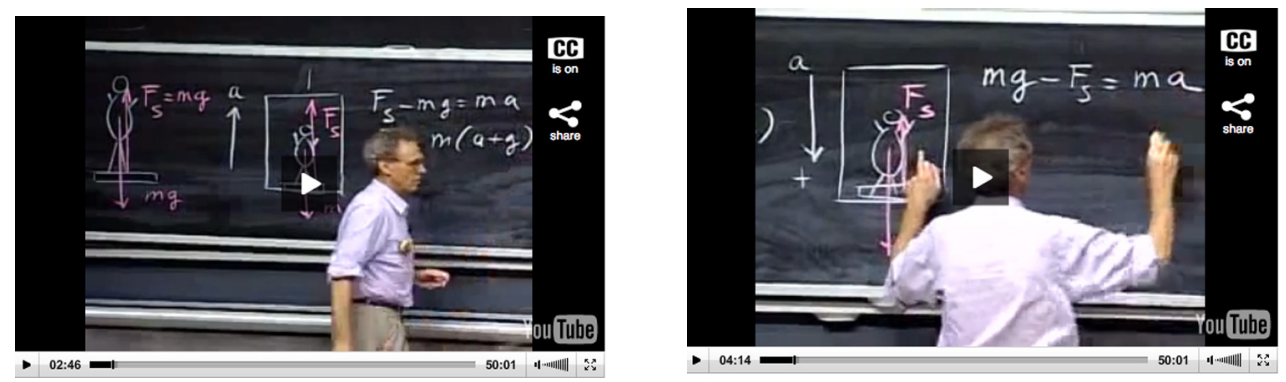

Figure 1: Prof. Lewin is introducing (verbally, visually and symbolically) the concept of the weight as the "force of scale" acting upwards on what is being weighing

Regarding controversial phenomenon of weightlessness, Prof. Lewin presents two types of demonstrations. The first type is low-tech carried out with a one - gallon water container. Initially, Prof. Lewin holds it in his hands, standing on the table (not very common position of a physics professor), and later jumps from the table, separating his hands slightly from the container (Figure 2). Not surprisingly, the container and Prof. Lewin fall in the same way, keeping their spatial configuration equal.
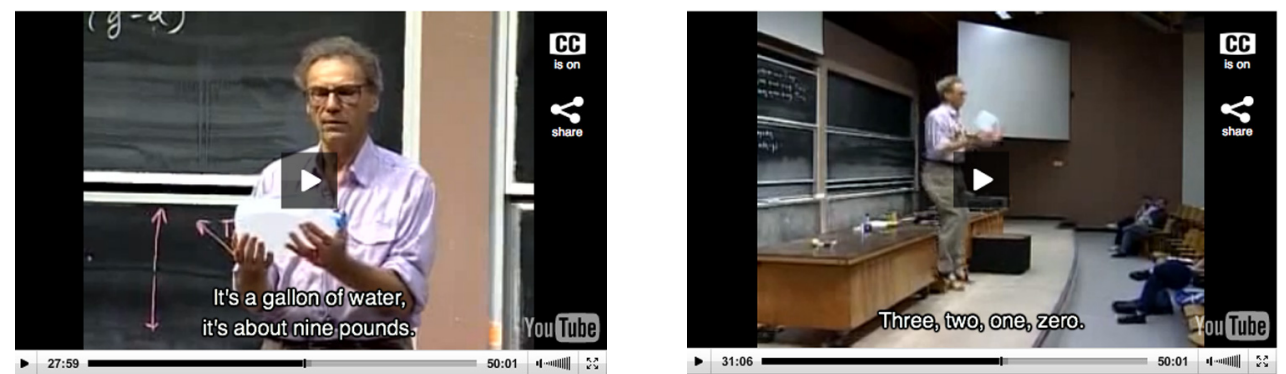

Figure 2: Prof. Lewin is performing a low-tech classroom demonstration of weightlessness of a gallon of water in free fall 
The second type of weightlessness demonstration is a high-tech one, showing that two sensitive electronic balances, in free fall, don't register a weight of an attached object. The balances were designed and made at MIT.

It is very important to stress that, before performing both type of demonstrations, Prof. Lewin tells students what they are going to observe.

In the third part, students are shown videos clips about weightlessness experiences of persons on board of a plane moving along a parabolic path with engines off.

The lecture is surely music for the ears of those who already know a lot of physics and are able to understand fine conceptual details and subtle comments. What is unknown, at least to me, is how successful was MIT students' conceptual learning about the phenomenon of weightlessness, checked with right probing questions. Namely, in other educational contexts, students usually have difficulties to gain sound understanding of why and how the bodies behave as weightless (Galili, 1995; Gürel \& Acar, 2003; Sharma et al., 2004; Tural et al., 2010)

\section{LEARNING RESULTS OF LECTURE-BASED TEACHING}

In fact, poor learning about weightlessness is not an exception but rather a part of general learning outcomes of traditional teaching (Wieman \& Perkins, 2005):

"... No matter how "good" the teacher, typical students in a traditionally taught course are learning by rote, memorizing facts and recipes for problem solving; they are not gaining a true understanding. Equally unfortunate is that in spite of the best efforts of teachers, typical students are also learning that physics is boring and irrelevant to understanding the world around them."

The diagnosis of unsatisfactory nature of learning results of lecture-based physics teaching can be stated in more specific terms (McDermott, 1991, 1993):

Conceptual learning is poor or absent.

Functional knowledge is not present.

Students are not able to apply high-order thinking procedures (like going from one to another representation or from abstract definitions and formulas to real word and back).

In addition, even in the domain of physics problem solving, a course part to which a considerable attention is given in traditional lectures, recitation sessions and exams, students mostly "conceptualize" it as a "plug-and-chug" game (Wells et al., 1995).

\section{WHY TRADITIONAL LECTURE-BASED PHYSICS TEACHING DOES NOT WORK WELL ENOUGH?}

The basic cause of failure is that this approach to teaching has behind it an erroneous theory of learning, which considers that the essence of learning is reception and memorizing of a clear instructional message. In other words, that approach does not take into account how humans learn (Bransford et al., 2001). It is almost a trivial fact that humans learn best by doing things, by making and correcting errors.

In order to do things perfectly, humans need to constantly improve their performances. Beside a lot of step-after-step practice, they also must think critically and creatively on what they do. It is well understood in sports and music. Nobody will learn to swim listening someone talking about swimming (and about Stokes' 
force) nor will someone learn to play violin listening someone talking about violin playing (and about Fourier transformations). Successful human learning is, in its very essence, an active process.

\section{WHAT IS ACTIVE PHYSICS LEARNING?}

Active physics learning (physics learning based on minds-on and hands-on activities) is gaining popularity in physics education, becoming a promising new paradigm which will, sooner or later, replace old paradigm codified in lecture-based teaching and passive learning. It is important to stress that active physics learning paradigm in physics teaching was not inspired and forced by general active learning movement in education (Bonwell \& Eison, 1991; Harmin, 1994). Physics education researchers invented it while trying to solve above-mentioned annoying issue of unsatisfactory conceptual students' learning that results from lecture-based teaching.

There are now enough experimental evidences that physics researchers were successful in solving the issue. Namely, activity and inquiry-based learning approach is obviously better than lecture-based teaching regarding conceptual learning (Hake, 1998; Deslauriers et al., 2011; Scott et al., 2013) and problem solving performances (Thacker et al., 1994; Hoellwarth et al., 2005).

What does physics instruction that promotes active learning entail? There are some general answers to this question, such as:

"... Instruction involving students in their own learning more deeply and more intensely than does traditional instruction, particularly during class time" (Meltzer \& Thornton, 2012),

"... Instructional method that engages students to shift from a passive to an active role in the learning environment" (Prince, 2004).

More informative and practical instructional approach has, as its starting point, the following pedagogical belief:

In order to learn physics, students should do physics: observe, describe, explain and predict physical phenomena.

In all these thinking processes, students make use of their previous ideas and experiences. When previous ideas do not work, students try new ones, proposed by them or by teacher. New knowledge is the result of sense making of new experiences. In order that this sense-making process comes out as a successful one, students should experience, and be conscious of, a "conceptual change" (Dykstra et al., 1992; Galili, 1996).

\section{EXAMPLES OF PHYSICS COURSES THAT PROMOTE ACTIVE LEARNING}

There is a lot of physics-course designs that, in general terms, promote active learning, although might differ in details.

Priscilla Laws (Dickinson College) designed the first lecture-free physics course, called "Workshop physics", in which students learn physics by doing physics (Laws, 1991, 1996, 1997). Students in the classroom, with the help of computers, take data about phenomena and make sense of them. Halliday \& Resnick textbook is used as a resource material to find out needed information. Its content is not lecture-based delivered to the students in the classroom. 
Eric Mazur (Harvard University) designed a method of active learning in which "students teach students" (Mazur, 1997). This is done through peer discussions of subtle points they did not understand by reading assignments (which replace delivery of content). Mazur only "teaches" those parts of the content which students did not comprehend by themselves.

Examples of some other courses that have accepted and implemented fully the paradigm of active physics learning are:

Student-Centered Active Learning Environment for University Physics or SCALE-UP, authored by Robert Beichner at the North Caroline State University (Beichner, 1999);

Technology-Enhanced Active Lerning or TEAL, designed by John Belcher at MIT (Dori \& Belcher, 2005), and

Investigative Science Learning Environment or ISLE, developed by Eugenia Etkina and Alan van Huevelen at the Rutgers (Etkina \& Van Heuvelen, 2007).

The first two courses were inspired greatly by the ground - breaking "physics studio" approach, designed and installed by Jack M. Wilson at the Rensselaer Polytechnic Institute (Wilson, 1994).

\section{PREDICT - OBSERVE — EXPlain: AN ACTIVE LEARNiNG SEQUENCE}

The most popular sequence of active learning is Predict - Observe - Explain. Explanation and prediction tasks were used long time ago by Piaget as diagnostic tools in his interview-based research on children's causal thinking (Piaget, 1930).

Nevertheless, the sequence was introduced into science teaching by White and Gunstone under acronym POE (Predict - Observe - Explain) (White \& Gunstone, 1992), without mentioning Piaget.

In order that this sequence works, it is necessary that students first have (according to their criterions) a meaningful situation about which they can answer questions. In answering such questions, students activate their intuitive ideas about how material world works or should work.

As can be concluded from its name, the Predict-Observe-Explain sequence consists of three steps.

1. In the first step, through prediction task about how a physical phenomenon or its simple modification will work, student personally activates and formulates his or her alternative ideas about considered physical phenomenon: What do I expect that will happen? Why do I expect that this must or might happen?

In this way, any student has an opportunity to predict personally an outcome of a simple experiment and to conceptually justifies his or her prediction. In this step, especially during elaboration of prediction justification, alternative ideas about functioning of particular segments of physical world are activated and explicitly formulated.

When personal predictions and justifications are formulated, then group discussion of those predictions and justifications comes, with the aim to reach consensus, meaning a group prediction and justification. It is important to tell students that everyone should keep personal prediction and justification, if not completely satisfied with different prediction and justification.

2. The second step is observation and comparison between personal and group prediction and observation. In the case of well thought learning situation, the 
prediction and observation do not coincide. When this happens, an "epistemological disequilibrium" has been produced and the students have concluded that their thinking about the studied phenomenon (or some of its modifications) is not adequate.

3. In the third step, students have a challenging task to explain the noted differences and to propose a change in the suppositions and reasoning their prediction was based on. The objective of the change is that the new prediction fits the observation.

My first illustration of Predict-Observe-Explain sequence implementation is students' consideration of the behavior of a jet that flows out of a plastic bottle through a hole made in its wall (Corona et al., 2006). Students are able to predict that the jet will stop to flow out if the bottle is in free fall, but the prediction schemes are not related to the weightlessness of water but to the same speed of the bottle and the water or to the ("increased") air pressure which keeps water in the bottle.

Nevertheless, even after the students saw that the jet stopped flowing out when the bottle was in free-fall, they do not expect that the jet will stop flow when the bottle is launched up. Their prediction, for the situation when the bottle is moving freely up, is that the jet will not stop flowing out but that the flow will be faster.

After seeing that their prediction does not fit the observation (the jet stops flow out also when the bottle is moving freely up), the students are ready to reconsider critically their situation model and explanatory schemes and to change them.

In my second illustration of the POE, students are asked to predict what will happen with a Pepsi-light can, that floats in water (Figure 3), if oil is poured in the jar.

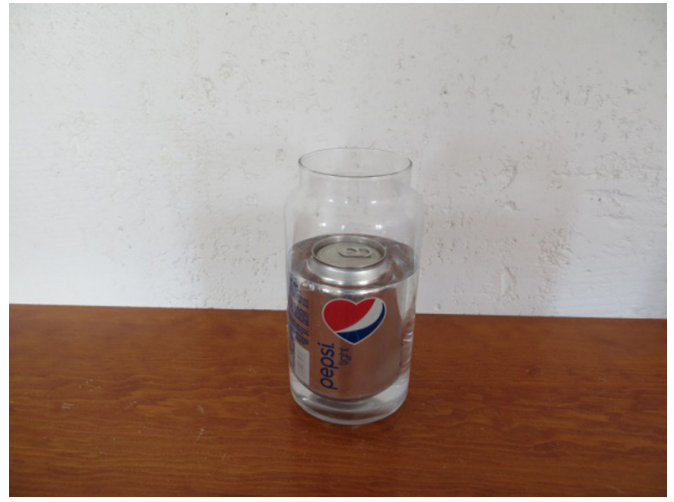

Figure 3: A Pepsi-light can floats in water

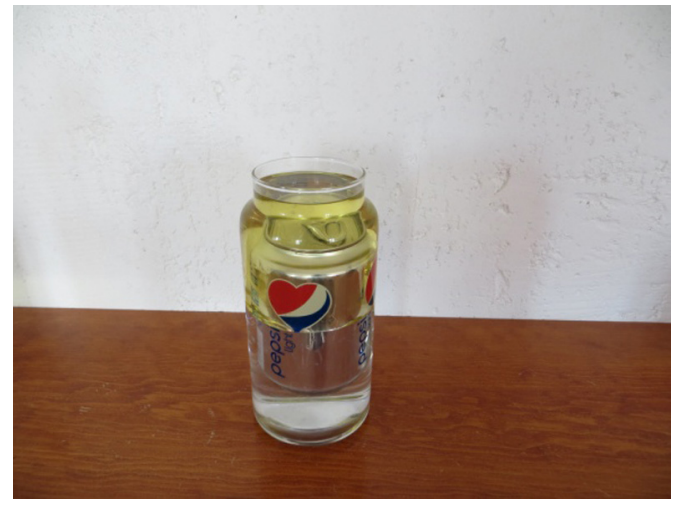

Figure 4: A Pepsi-light can levitates in water and oil

Many students believe that the floating can, having oil pressing down, should go deeper in water. Some even predict that the can will be below the water surface. Observation is quite different: the can rises higher (Figure 4), previously under the surface "Pepsi red-white-blue heart" goes out of water. That consequence of oil pouring is almost a miracle for students. The construction of an adequate qualitative explanation is not an easy task. All students know to recite Pascal principle but fail to activate it and apply it this context. Hydrostatic oil pressure on the water surface is bigger than on the upper surface of the can and the pressure is transmitted through the water increasing the pressure on the bottom of the can. 
Recently an interesting variation of POE learning sequence was suggested (Bonello \& Scaife, 2009). Its acronym PEOR stays for Predict - Explain - Observe React. The most important part of is naturally R-phase in which students can reinforce, revisit o rethink their initial ideas or test, change or reinforce new ideas.

\section{FAST AND SLOW THINKING: A BROADER VIEW ON STUDENTS THINKING IN PHYSICS LEARNING}

As students frequently "fail" in their predictions, it is useful to stress to them the importance of being able to formulate and know own ideas, even if they initially look out as unproductive. In fact, it seems that humans' thought production is carried out by two very different systems. Kahneman, Nobel Prize winner for economics, in his best-selling book "Thinking, fast and slow" (Kahneman, 2011), describes (and gives research-based evidence of) facets of two different modes in which human brains operate when answering questions and solving challenging problems:

System 1 is fast, automatic, frequent, emotional, stereotypic and subconscious.

System 2 is slow, effortful, infrequent, logical, calculating and conscious.

Sparing their mental energy, humans routinely use System 1 for level of thinking needed by common-type actions (driving a car or buying groceries). Students do the same in their first try to answer "easy" school questions (which body, heavy or light one, will fall faster towards the ground?).

A common person calls System 2 into action only when System 1 recognizes that a problem can't be solved in stereotypical approach.

Active physics learning is a great opportunity for students to learn about normality of System 1 activation and to start to use System 2 more frequently. That is not an easy task and we should be very patient with students, because even scientists are not always able to resist the "siren's song" of the System 1.

Namely, in essence, modern training of future scientists is (or should be!) their systematic preparation in using System 2 routinely. Nevertheless, to assure a desired accuracy level of scientific production, many quality control mechanisms are in place in scientific journals, being thought out as a collective protective bell against writings in which scientists' thinking, in some "weak moments", was too fast and carried out by the System 1. After years of practice, many scientists are able to use almost exclusively the System 2 in preparing their research publications.

Surprisingly, some of them, when writing physics textbooks, especially when inventing end-of-chapter problems, give chance and voice to their System 1 and make errors they would hardly be allowed to have in a published journal article. Alarming enough, some rather trivial errors, measured by professional standards, are repeated in various editions of the same textbooks (Slisko, 2011) and some others lived in various physics textbooks for centuries (Slisko, 2010).

A very instructive example of fast thinking universality is common answer which many today's students (and some teachers) give to very old "snail problem". Here it comes in its easy, round-number version:

A snail, driven by an unknown reason, decided to climb a 10-meter wall. During the day, it climbs 3 meters, but during the night it falls back 2 meters. After how many days and nights, will it reach the top of the wall?

a) 10 days and 10 nights;

b) 10 days and 9 nights; 
c) 8 days and 7 nights;

d) 4 days and 1 night.

Well known wrong answer "10 days and 10 nights" is obtained by an "obvious" reasoning: During one day and one night the snail climbs 1 meter. If it should climb 10 meters, the needed climbing time "must be" 10 times bigger. Slow thinking gives another result. During seven days and seven nights the snail climbs seven meters. At the end of the eighth day, after climbing missing three meters, the snail will reach the top.

What is not so widely known (but surely should be!) is that the fast-thinking students' answer was "professional answer" given by mathematicians to different formulations of this problem during a few centuries, for example, in Italy from early 13 th century to late 15th century (Singmaster, 2004). Among those mathematicians was also Fibonacci, one of the best in the Middle Ages. In his famous textbook "Liber abaci", published in 1202, he formulated the problem this way:

"On the Lion Who Was in a Pit

A certain lion is in a certain pit, the depth of which is 50 palms, and he ascends daily $1 / 7$ of a palm, and descends $1 / 9$. It is sought in how many days will he leave the pit." (Sigler, 2003: p. 273)

Using the same fast-thinking approach as today's students, Fibonacci finds the difference between $1 / 7$ and $1 / 9$, obtaining $2 / 63$. After that he divides 50 with $2 / 63$ to get the answer of 1.575 days. Nevertheless, slow-thinking answer is 1.572 days and 1.571 nights.

I will add one more example of fast-thinking phenomenon connected with the snail problem, taken from a recent published book "Games and mathematics. Subtle connections" (Wells, 2012), written by David Wells, former Cambridge student, chess champion and prolific author of many popularization books on mathematics. The book, issued by one of the world best publishing company, has the following review:

"Wells notes that mathematicians use analogy and other play techniques as they construct proof. He draws the reader to a new appreciation of proof - not mere certification of correctness but a deeper exploration of the mathematical world. Games and Mathematics makes an important advance in communicating the nature of mathematics. It contains a profound message for philosophers of mathematics, but all mathematically-inclined readers will find Games and Mathematics as compelling as Wells' excellent 'Curious and Interesting' books."

Dr. Paul Brown, Carmel School, Perth, Western Australia and Author of "Proof: Interesting Activities in Conjecture and Mathematical Proof"

After such a review, nobody would expect that Wells would offer an incorrect, fast-thinking answer to his formulation of the snail problem (p. 4):

"Another traditional puzzle appeals to me because it sets the solver a trap, albeit a rather obvious one. Here is one version. A snail - or a serpent or a frog! — lies at the bottom of a well, 30 units deep. It climbs 6 units every day but falls back 3 units every night. How long does it take to escape from the well? The obvious answer is that the snail rises 3 units every day-and-night, on balance, so it takes 10 days-and-nights to escape, but this is wrong because it will actually reach the top of the well half-way through the $10^{\text {th }}$ day and after only 9 nights."

Slow-thinking answer is different. During eight days and eight nights, the snail would climb up to 24 units and during the ninth day, after climbing missing 6 units, would reach the top. 


\section{The ESSENCE OF ACTIVE LEARNING: SELF-REGULATED}

\section{LEARNING HOW TO LEARN}

As the snail problem shows, fast thinking is very hard to be freed off. Mind, as many of us, first wants to try to carry out mental tasks in the most effortless way. It seems to me that the road toward slow thinking can be better walked if we help students learn how authentic human learning works. In order to make successful experiments with their own learning to improve it, only practice of active learning is not enough. They should also learn about its theory.

Active physics learning, as actually designed and practiced in physics education, might be improved, both at students' and teachers' side, if it is informed about a more complex and much elaborated educational construct, called "self-regulated learning" (Pintrich, 1995; Low \& Jin, 2012; Zimmerman \& Schunk, 2013).

So, a very challenging and far-reaching approach to design of active physics learning would be to inform students much more about the complexity of the learning and thinking process, fast and slow thinking are only a top of an iceberg. That would be done best, if we design opportunities for the students to plan, practice and observe their own learning within the self-regulation paradigm.

Regarding metacognitive aspects of learning, self-regulated learners plan, set goals, organize, self-monitor, and self-evaluate gained results at various points during the learning process. They are also very motivated, showing high self-efficacy, selfattribution and intrinsic task interest. In addition, self-regulated learners know and accept that learning results are better with more efforts and persistence and inside of an adequate learning environment (Zimmerman, 1990). The success of self-regulated learning depends of students' abilities to activate and use in the best way metacognitive, motivational and behavioral resources and strategies.

According to Zimmerman (2002), self-regulated learning process consists of three different phases:

- Forethought or planning phase;

- Performance phase; and

- Self-reflection phase.

In the Planning phase, students activate all necessary knowledge and skills to understand the given problem and make a plan how to solve it.

In the Performance phase, they monitor how they perform, whether some unexpected or unclear details appear, and verify validity of partial and final solution.

Self-reflection phase is the most important part of self-regulated learning. In it, students are supposed to look back and evaluate critically their performance and what was learned and what was not. In the last phase, they try to determine what possible causes of their unsuccessful learning might be. In order to assist students in their self-reflective performance, we should provide students with an adequate and timely feedback at every stage of implemented learning sequence.

In addition, formative and summative assessment should award personal ideas and arguments not only for correctness but also for clearness or originality. Students appreciate when we are interested in what and how they think and when their initial thinking is not punished or subject of laugh. Freedom of thinking, which includes an explicit right to err, is the first precondition of any learning.

Learning from self-recognized and self-corrected personal and group errors seems to be a better way to construct knowledge and skills than direct instruction (Kapur, 2012; Siler et al., 2013). 


\section{WHAT ARE SOME EFFECTS OF ACTIVE PHYSICS LEARNING?}

In his doctoral research, Dr Mirko Marušić, then a high-school physics teacher in Split (Croatia), explored, under my mentorship, different effects of two designs of active learning experiences: Read - Present - Question (RPQ) and Experiment Discuss (ED). The topics of the RPQ group were actual CERN experiments. The topics of the ED group were simple phenomena for which students hold strong intuitive ideas which differ from scientific ones.

The research was carried out during one semester (16 weeks), within one 45minute session per week. Interested readers can find more details about students, curriculum and treated themes, in the articles cited below.

In brief, the ED group outperformed the RPQ group in

Classroom Test on Scientific Reasoning (Marusic \& Slisko, 2012a);

Colorado Learning Attitude about Science Survey (Marusic \& Slisko, 2012b);

Changing negative attitude towards attractiveness of school physics (Marusic \& Slisko, 2012c); and

Changing negative attitude towards physics as profession (Marusic \& Slisko, 2012d).

Although the analysis is still under way, preliminary results indicate that students initially believed that physics learning helps in developing logical thinking but not creative thinking. After active learning experiences, the students in ED group made much bigger attitudinal change towards the relationship between physics learning and creative thinking. The change in concrete thinkers' attitude is very characteristic. In the RPQ group, concrete thinkers after learning experiences with modern physics topics believe less that physics learning has something to do with development of creative thinking. In ED group the situation is quite opposite. Concrete thinkers made bigger relative attitudinal improvement regarding creativity development.

To measure that attitude and its change, students had to express their justified opinions regarding the statement:

"I feel good while learning physics because it helps me to develop my creative thinking."

The students could choose one option on a 5-point Likert scale:

(a) I strongly disagree (graded as "-2"); (b) I disagree ("-1"); (c) Neutral ("0"); (d) I agree ("+1"); and (e) I strongly agree ("+2").

Only in ED group, there were cases of total attitudinal change. Below come three of them:

\section{STUdent 1}

Pre: (-2) I don't feel well in physics classes because it is boring. This also means there is no creativity, no creative thinking.

Post: $(+2)$ I feel good in physics classes that look like a game. It makes it always exciting and encourages us to think creatively with no fear of bad grades.

\section{StUdent 2}

Pre: (-2) Studying physics may develop logical but definitely not creative thinking. Everything is predefined. I can fantasize about "what if" but that is not physics. 
Post: $(+2)$ Creativity is very much present in physics. It was nice to experience that creative thinking is possible in physics classes as well (debate, analyzing everyday life examples, interesting experiments...).

\section{STUDENT 3}

Pre: (-2) Creativity in physics that I know does not exist. It may be present in physics in general but I don't find it in physics as a school subject.

Post: $(+2)$ Creative thinking processes in physics classes surprise me. We were asked to explain the experiments in from of the class. It was creative and even interesting (funny at times). It is a great feeling!

\section{How TO PROMOTE STUDENTS' CREATIVITY IN ACTIVE PHYSICS LEARNING?}

In the above-commented pilot research, we did not explore students' personal definitions of creativity, believing that a common-sense notion of creativity (generation of novel and useful ideas and products) is shared by majority of them.

In addition, our hypothesis was that active physics learning would help students to discover and feel their own creative potentials.

In the group that performed and discussed experiments with easy-to-find ordinary objects that happened much more than in the group in which students were reading and presenting information about sophisticated physics experiments carried out at the CERN. This is an important initial result which shows that active physics learning can contribute to improve attitude students have towards the relationship between physics learning and development of creative thinking. Students are more likely to connect creativity and physics learning when they do physics, no matter how simply is to carry out and modify physical phenomena studied, than when they read about physicists do cutting-edge physics with extremely sophisticated technology.

Now, more than ever before, it is clear to many that creativity can't be only nicelooking decorative element among other educational objectives. Everybody agree that today's and tomorrow's economic, social, nutritional and medical problems of modern world can only be solved by ever-increasing personal and collective creative thinking. Such a cultural change would be impossible if "teaching and learning creativity" isn't present in classroom on daily basis.

Nevertheless, such a task is far from being simple because there are many hard implementation questions. For teachers, the most important are:

a) How to have real and adequate presence of creativity in curriculum?

b) How to teach creativity in effective ways?

c) How to evaluate progress in creativity thinking of students?

Due to the fact that psychological processes, which creativity thinking and behavior are based on, are extremely difficult to define, explore and evaluate (Runco, 2004; Hennessey \& Amabile, 2010), these important questions have by now only initial answers (Piirto, 2011; Gregerson et al., 2013; Barbot et al., 2011). In addition, some "practical" suggestion for classroom building of students' creativity are either too numerous (Cheng, 2004) or too general (Gregory et al., 2013). 


\section{Creativity in PROBlem SOLVING}

In my own teaching, at the very beginning, I define creativity operationally as nonroutine thinking. To give meaning to this "negative" definition of creativity, students have first to experience what routine thinking is and what its limitations are.

The best way to show it is to present good puzzles to students. Their usefulness comes from the fact that they are easily understandable and usually do not require specific-content knowledge for their solution.

When students approach a puzzle within routine, fast thinking, they either get wrong answer or conclude that it is impossible to answer it. An acceptable answer, of course, can be found only by using non-routine thinking. That is an "Eureka moment" for many students. It comes as an award for initial common-felt frustration when they were in routine-thinking phase.

According to many authors, multiple experiences with transitions between routine and non-routine thinking, when followed by related epistemological discussions and reflections, help students in "improving thinking, learning and creativity" (Bransford \& Stein, 1993), learning about "the art and logic of breakthrough thinking" (Perkins, 2000) and making progress in "critical thinking, mathematics, and problem solving" (Michalewicz \& Michalewicz, 2008).

Connecting creativity and non-routine thinking give me opportunity to help students discover that they are much more creative than they usually think. Namely, many of them connect creativity only with big artistic and scientific creations. In addition, they discover that they can improve such-defined creativity. That is best practiced with the problems that can be solved in routine (algorithmic) ways, but whose solution is much simpler or interesting by using non-routine (creative) approach. Asking for and praising alternative solutions of problems, in my view, give students an opportunity to build disposition for and to practice creative thinking.

When students acquire sufficient content knowledge, then they can explore and improve their creative potential solving "physics puzzles". These are calculation or practical physics problems that, at first sight, look impossible to solve:

Is it possible to determine mean density of Earth using a satellite and a chronometer?

Is it possible to determine relative density of oil using a plastic tube and a ruler?

Is it possible to determine the depth of a lake using only graduated test tube?

As in the case of ordinary puzzles, routine thinking (to determine density one needs to measure mass and volume) is an obstacle for finding the solution. Nonroutine or creative thinking is necessary in order to find out surprising fact that there exists a relationship between mean Earth density and the period of a satellite, with no other physical quantity involved. That makes possible to calculate mean density when the value of the period is measure by a chronometer.

\section{LIFTING TWO GLASSES BY ONE BALLOON: AN EXAMPLE OF STUDENTS' PEDAGOGICAL CREATIVITY}

Physics students at my University are exposed mainly to the traditional lecturebased teaching. So, it is not a wonder that, in their first try to prepare and present potential engaging demonstrations for middle-school pupils, the students think that the most important part of them is a "clear and logical" explanation of the physics behind demonstrations. Because of such a belief, in the course "Physics teaching" (an obligatory methodic course for all physics students!), I have to help students' 
develop "pedagogical creativity": an ability to use in novel and appropriate way known physics demonstrations. "Appropriate way" means that presentation of a demonstration should be designed in the form that is likely to motivate and engage pupils in active physics learning.

In the course offered in Spring of 2005, the student Sergio Rivera Hernández designed the best sequence. The account which follows is revised version of the presentation which Sergio and I presented the same year at the International Workshop "New Trends in Physics Teaching" (Rivera Hernández \& Slisko, 2005).

Sergio started his demonstration by putting on the table a glass (in vertical position) and a desinflated balloon. The he asked: Is it possible to lift the glass using the ballon?

After a while, other students figured out a right answer. The ballon is put in the glass and inflated. When the balloon presses the wall of the glass strongly enough, it is possible to lift the glass by lifting the neck of the balloon. (Figure 5).

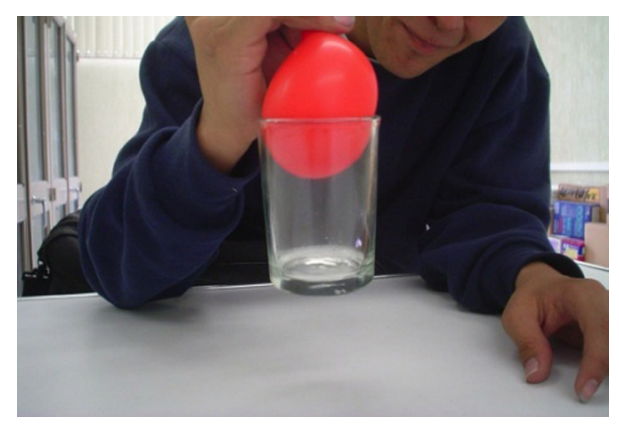

Figure 5: Lifting one glass by the balloon

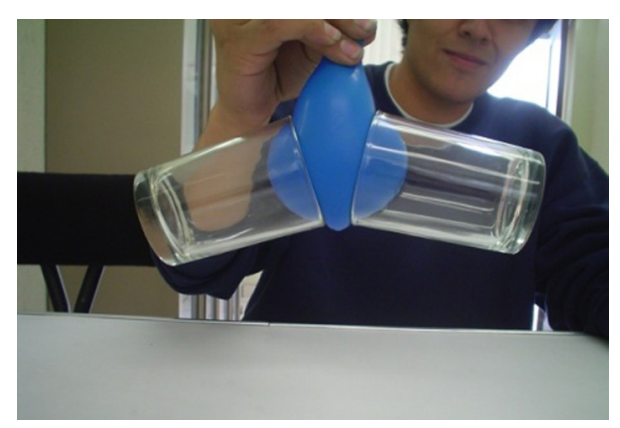

Figure 6: Lifting two glasses by the balloon

After that, a serious challenge came. Sergio put on the table two glasses in vertical position and asked: Is it possible to lift these two glasses using one balloon?

In the first moment, it was a real puzzle for all and nobody had an idea how to lift two glasses. After some time, there were a few unsuccessful tries. A student wanted to use routine solution. She tried to force one glass into other in order in order to lift them together. She pressed so strongly and broke one glass. Finally, we all had to admit that we were totally clueless.

Sergio took two glasses and put them in horizontal position, with their openings near one to other. The he put the ballon between the glasses and inflated it. It was possible to lift two glasses (Figure 6). We all were delighted with the solution which appears to be a simple one when one sees it, but it is extremely hard to find if one follows routine thinking.

After some other students repeated to solution themselves, they had task to discuss the physical mechanism responsible for glass lifting. Students came with two causal models. In the "friction model", the friction force between the inflated balloon and the glass wall doesn't allow separation of the glass and the ballon. In the "pressure difference model", the separation of the glass and the balloon was not possible because of reduced pressure of the air in the glass. That was an ad hoc "theory" because students didn't have any idea what caused that reduced pressure.

The next task was to design experimental tests of two proposed causal mecanisms. One proposal was the following:

If the lifting is due to friction force, it will not work if the friction is reduced drastically. 


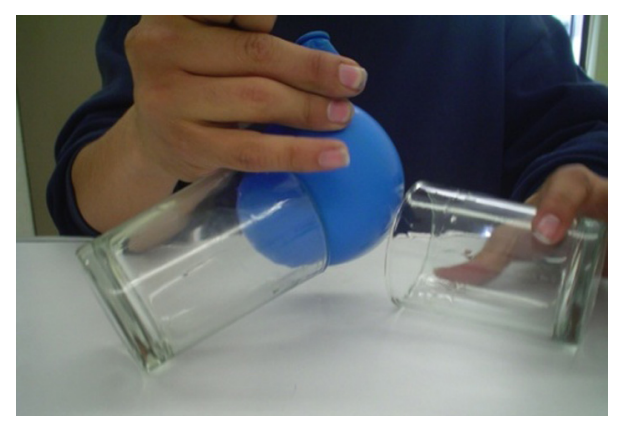

Figure 7: The oiled glass couldn't be lifted

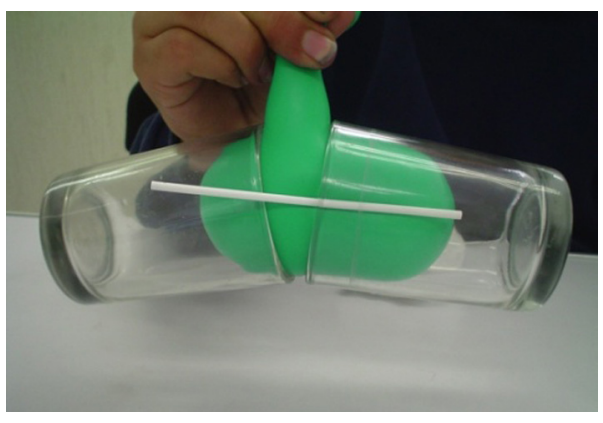

Figure 8: Equalizing pressure does not make change

To check it, students oiled one glass. The result was that the balloon could lift un-oiled glass but not the oiled one (Figure 7). This experiment confirmed predictive power of "friction model".

Students argued that if the cause of lifting is the reduced pressure in the glass, then if the pressure in the glass is made equal to the atmospheric pressure, the glass wouldn't be lifted. That prediction was checked in the following way. A strong plastic straw was placed between the glass and the balloon, connecting the air in the glass with air outside. That made both pressures equal, without destroying "lifting power" of the balloon (Figure 8). This experiment reduced the credibility of the "pressure difference model".

I consider that both purposeful preparation of engaging demonstrations and discussion and design of experiments, that are necessary to understand better the physics which make demonstrations possible, are adequate and act in complementary fashion to promote students' pedagogical and scientific-thinking creativity.

\section{WEIGHTLESSNESS IN CLASSROOM: ANOTHER OPPORTUNITY FOR STUDENTS' CREATIVITY}

In the course "Physics teaching" students freely choose which demonstration might be engaging for middle-school pupils. They have another opportunity for showing their pedagogical creativity. It happens after they learn about "Bottle in free-fall" demonstration of weightlessness. After getting a clear idea why it happens, as a transfer test, they should design a different free-fall demonstration of weightlessness. I will present a few of students' proposal.

The first is "magnetic demonstration", whose initial idea was proposed by the student Heladio Ayala. Two neodymium magnets (Figure 9) are placed in the plastic tube, one fixed on the top and other movable on the bottom. When the tube is at rest, the upper magnet is unable to lift the lower magnet. In free-fall, the lower magnet is attracted upwards (Ayala et al., 2011).

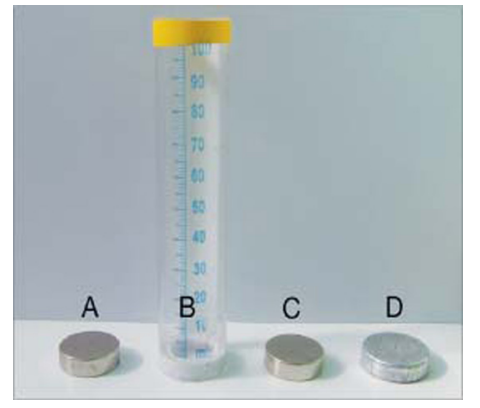

Figure 9: Items needed for magnetic

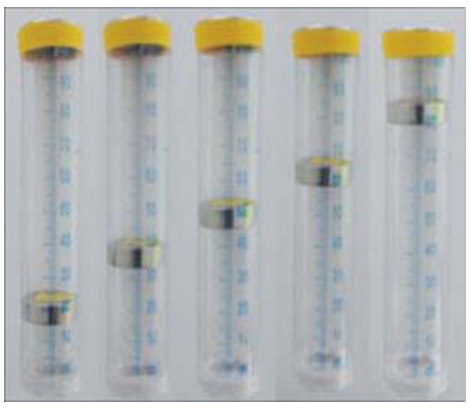

Figure 10: The lower magnet is attracted upwards. Demonstration of weightlessness 


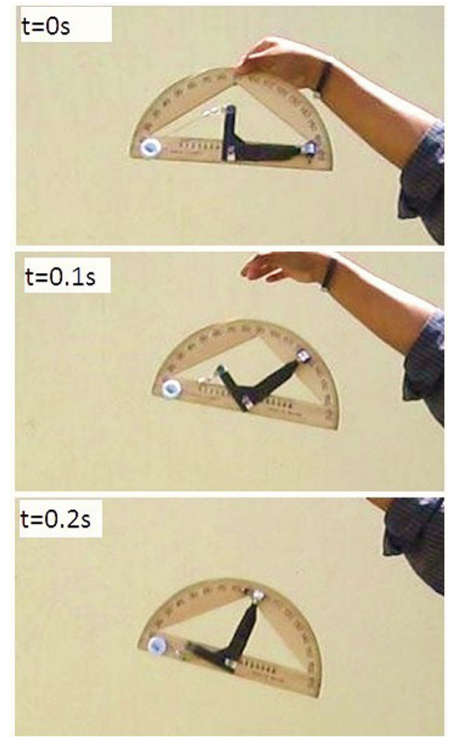

Figure 11: Demonstration with a protractor
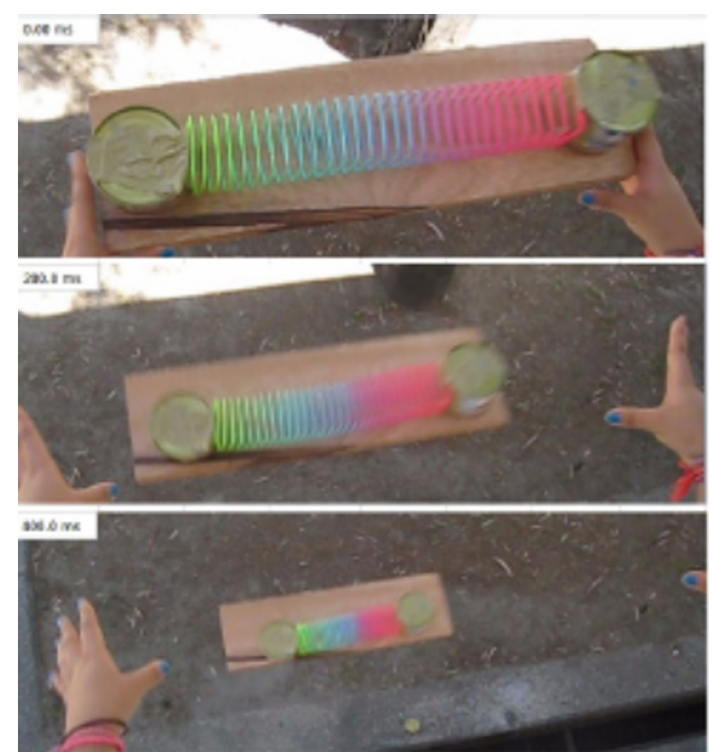

Figure 12: Demonstration with a slinky and two cans

The student Eric F. Jiménez Andrade proposed a demonstration with a protractor, a hard cardboard in the form of an L, a spring and a weight. When the protractor is at rest, the weight and the spring keeps the longer arm of the cardboard in horizontal position. In free-fall, the cardboard starts to rotate, because the weight becomes weightless (Figure 11).

The students Adriana Pérez Martínez and Raúl Felipe Maldonado Sánchez proposed a demonstration with a slinky, wood board and two cans. Two cans are attached to the extended slinky and placed on the board.

When in rest, the friction between the cans and the board prevents the slinky from contracting.

In free fall, the cans don't press the board, the friction disappears and the slinky contracts (Figure 12).

Not all proposals were successful. For example, some students thought that a bubble in free-falling bottle should be motionless, because the buoyant force would disappear. They based their design of a weightlessness demonstration on the slowthinking idea "no force - no motion".

Video recording with high-speed camera and a frame-after-frame analysis, performed by Adrian Corona, show that the bubble continues to move up even after the buoyant force was switched-off in free-fall (Figure 13).

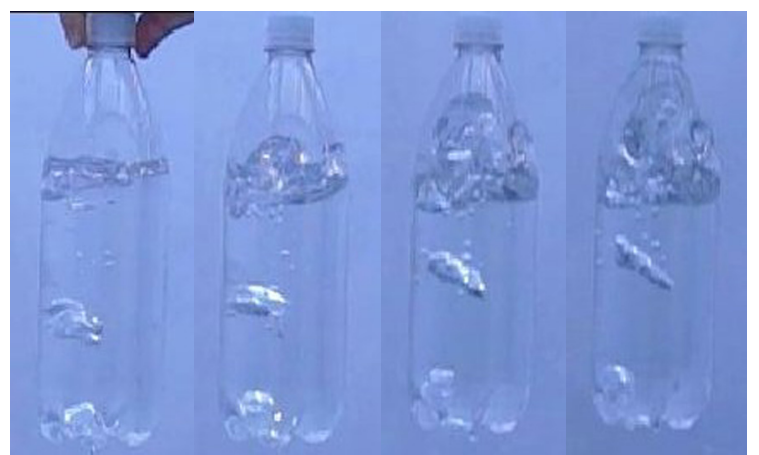

Figure 13: The bubble continues to move upwards even in the free-fall 


\section{Conclusions}

According to my experience, active physics learning is able to accelerate students' cognitive growth, make positive changes in students' attitude towards physics and to improve their conceptual understanding and creative thinking. I am always glad to learn students' unexpected and amazing ideas. In addition, it makes me happy when students' enjoy learning and when they reveal anonimously that they share the joy or learning with parents, brothers, boyfriends and girlfriends.

To further develop active physics learning, we should work more exlicitly on informing students about all complexity of human learning. The paradigm of selfregulated learning has a lot results which might be useful for designing improved active learning sequences.

On the other side, active physics learning should not be preferent pedagogical approach in only one or a few courses. It should be rather a basic element of institutional policy in the domain of learning and teaching. Such an institutional acceptance is neither fast nor easy, due to many "obvious" counter arguments. Seemingly the most solid, cost-effectiveness of lecture-based teaching, was proven to be false (Wilson, 1994). Changes made in Prof. Lewin's video course in its edX version, by which some elements of explicit students' mental activities in video watchings were introduced, are certainly a very good news (Belcher, 2013). Let's hope that in the future we will lecture less and students will lear more.

\section{ACKNOWLEDGEMENT}

This article is partially based on the results of Josip Slisko's sabbatical research project "Active physics learning on line" supported by CONACyT Mexico in the period August 2012-July 2013.

The author would like to thank Dr. Marina Milner-Bolotin, from the University of British Columbia, Vancouver, for her insightful comments and suggestions.

\section{REFERENCES}

Argyris, C. (1991). Teaching smart people how to learn. Harvard Business Review, 4(2), 99-109.

Ayala, H., Slisko, J. \& Corona, A. (2011). Magnetic demonstration of weightlessness: A spark of student creativity. The Physics Teacher, 49 (8), 524-525.

Barbot, B., Besançon, M. \& Lubart, T. I. (2011). Assessing Creativity in the Classroom. In The Open Education Journal 4, Supplement 1: M5, 58-66.

Beichner, R. J. (1999, unpublished). Student-Centered Activities for Large-Enrollment University Physics (SCALE UP). Lecture presented at the Sigma Xi Forum: Reshaping Undergraduate Science and Engineering Education: Tools for Better Learning, Minneapolis.

Belcher, J. (2013). MIT Physics Department's experience with edX. MIT Faculty Newsletter, 26(1), 12-14.

Bonello, C. \& Scaife, J. (2009). PEOR: Engaging students in demonstrations. Journal of Science and Mathematics Education in Southeast Asia, 32(1), 62-84. 
Bonwell, C. C. \& Eison, J. A. (1991). Active learning. Creating excitement in the classroom. Washington: The George Washington University.

Bransford, J. D., Brown, A. L. \& Cocking, R. R. (Eds.). (2001). How people learn. Brain, mind, experience, and school. Expanded edition. Washington, D.C.: National Academy Press.

Bransford, J. D. \& Stein, B.S. (1993). The ideal problem solver. A guide for improving thinking, learning and creativity. New York: W. H. Freeman \& Company.

Cheng, V. M. (2004). Developing physics learning activities for fostering student creativity in Hong Kong context. Asia-Pasific Forum on Science Learning and Teaching, $5(2), 1-33$.

Corona, A., Sliško, J. \& Planinsic, G. (2006). Rising freely bottle also demonstrates weightlessness. Physics Education, 41(3), 8-9.

Deslauriers, L., Schelew, E. \& Wieman, C. (2011). Improved Learning in a Large-Enrollment Physics Class. Science, 332(6031), 862-864.

Dori, Y. J. \& Belcher, J. (2005). How does technology-enabled active learning affect undergraduate students' understanding of electromagnetism concepts? The Journal of the Learning Sciences, 14(2), 243-279.

Drucker, P. F. (1999). Knowledge-worker productivity: The biggest challenge. California Management Review, 41(2), 79-94.

Drucker, P.F. (2005). Managing Oneself. Harvard Business Review, 83(1), 100-109.

Dykstra, D. I., Boyle, C. F. \& Monarch, I. A. (1992). Studying conceptual change in learning physics. Science Education, 76(6), 615-652.

Etkina, E. \& Van Heuvelen, A. (2007). Investigative science learning environment - A science process approach to learning physics. In Redish, E. F., Cooney, P. J. (Eds.), Research-based reform of university physics. College Park, MD: American Association of Physics Teachers.

Galili, I. (1995). Interpretation of students' understanding of the concept of weightlessness. Research in Science Education, 25(1), 51-74.

Galili, I. (1996). Students' conceptual change in geometrical optics.International Journal of Science Education, 18(7), 847-868.

Galili, I. (2001). Weight versus gravitational force: Historical and educational perspectives. International Journal of Science Education, 23(10), 1073-1093.

Gautreau, R. \& Novemsky, L. (1997). Concepts first - a small group approach to physics learning. American Journal of Physics, 65(5), 418-428.

Graham, P. A. (Ed.). (2002). Knowledge Economy and Postsecondary Education: Report of a Workshop. Washington, DC: National Academic Press.

Gregerson, M. B., Snyder, H. T. \& Kaufman, J. C. (2013). Teaching Creatively and Teaching Creativity. New York: Springer.

Gregory, E., Hardiman, M., Yarmolinskaya, J., Rinne, L. \& Limb, C. (2013). Building creative thinking in the classroom: From research to practice. International Journal of Educational Research, 62, 43-50.

Gürel, Z. \& Acar, H. (2003). Research into students' views about basic physics principles in a weightless environment. Astronomy Education Review, 2(1), 65-81. 
Hake, R. R. (1998). Interactive-engagement versus traditional methods: A six-thousand student survey of mechanics test data for introductory physics courses. American Journal of Physics, 66(1), 64-74.

Harmin, M. (1994). Inspiring active learning. A handbook for teachers. Alexandria: Association for Supervion and Curriculum Development.

Hennessey, B. A. \& Amabile, T. M. (2010). Creativity. Annual Review of Psychology, 61, $569-598$.

Hoellwarth, C., Moelter, M. J. \& Knight, R. D. (2005). A direct comparison of conceptual learning and problem solving ability in traditional and studio style classrooms. American Journal of Physics, 73(5), 459-463.

Jarvis, P. (Ed.). (2001). The Age of Learning: Education and the Knowledge Society. London: Taylor and Francis Group.

Kahneman, D. (2011). Thinking, fast and slow. New York: Farrar, Straus and Giroux.

Kapur, M. (2012). Productive failure in learning the concept of variance. Instructional Science, 40(4), 651-672.

Keeling, R.P. \& Hersh, R.H. (2012). We're Losing Our Minds. Rethinking American Higher Education. New York: Palgrave Macmillan.

Lewin, W. (2012). For the Love of Physics: From the end of the rainbow to the edge of time - a journey through the wonders of physics. New York: Simon and Schuster.

Lewin, W. (1999). Lecture 7. Available at http://ocw.mit.edu/courses/physics/8-01physics-i-classical-mechanics-fall-1999/video-lectures/lecture-7/

Laws, P. (1991). Workshop Physics: Learning introductory physics by doing it. Change: The Magazine of Higher Learning, 23(4), 20-27.

Laws, P. W. (1996). Workshop Physics Activity Guide Modules 1-4, New York: John Wiley and Sons.

Laws, P. W. (1997). Millikan Lecture 1996: Promoting active learning based on physics education research in introductory physics courses. American Journal of Physics, 65(1), $14-21$.

Low, R. \& Jin, P. (2012). Self-regulated learning. In Encyclopedia of the Sciences of Learning (3015-3018). New York: Springer.

Marusic, M. \& Slisko, J. (2012a). Influence of three different methods of teaching physics on the gain in students' development of reasoning. International Journal of Science Education, 34(2), 301-326.

Marusic, M. \& Slisko, J. (2012b). Effects of two different types of physics learning on the results of CLASS test. Physical Review Special Topics: Physics Education Research, 8(1), 010107.

Marusic, M. \& Slisko, J. (2012c). Increasing the attractiveness of school physics: The effects of two different designs of physics learning. Revista Mexicana de Física E, 58(1), $75-83$.

Marusic, M. \& Slisko, J. (2012d). Many high-school students don't want to study physics: active learning experiences can change this negative attitude! Revista Brasileira de Ensino de Física, 34(3), 3401.

Mazur, E. (1997). Peer Instruction: A User's Manual. New Jersey: Prentice Hall. 
McDermott, L. C. (1991). Millikan Lecture 1990: What we teach and what is learned Closing the gap. American Journal of Physics, 59(4), 301-315.

McDermott, L. C. (1993). Guest Comment: How we teach and how students learn - A mismatch? American Journal of Physics, 61(4), 295-298.

Meltzer, D. E. \& Thornton, R.K. (2012). Resource letter ALIP-1: Active-learning instruction in physics. American Journal of Physics, 80(6), 478-496.

Michalewicz, Z. \& Michalewicz, M. (2008). Puzzle-based learning: Introduction to critical thinking, mathematics, and problem solving. Melbourne: Hybrid Publishers.

Perkins, D. (2000). Archimedes' bathtub. The art and logic of breakthrough thinking. New York: W. W. Norton \& Company.

Piaget, J. (1930). The child's conception of physical causality. Oxford: Harcourt, Brace \& Company.

Piirto, J. (2011). Creativity for $21^{\text {st }}$ century skills. How to embed creativity into the curriculum. Rotterdam: Sense Publishers.

Pintrich, P. R. (1995). Understanding self-regulated learning. New directions for teaching and learning, 63, 3-12.

Prince, M. (2004). Does active learning work? A review of the research. Journal of Engineering Education, 93(3), 223-231.

Rivera Hernández, S. \& Slisko, J. (2005). Levantar dos vasos mediante un globo: usando un truco de fiestas para enseñar y aprender la naturaleza de la física. Memorías del taller internacional "Nuevas Tendencias en la Enseñanza de la Física". Puebla: Facultad de Ciencias Físico-Matemáticas.

Runco, M. A. (2004). Creativity. Annual Review of Psychology, 55, 657-687.

Scott, T., Gray, A. \& Yates, P. (2013). A controlled comparison of teaching methods in first-year university physics. Journal of the Royal Society of New Zealand, 43(2), 88-99.

Sharma, M. D., Millar, R. M., Smith, A. \& Sefton, I. M. (2004). Students' understandings of gravity in an orbiting space-ship. Research in Science Education, 34(3), 267-289.

Sigler, L. E. (2003). Fibonacci's Liber Abaci. Leonardo Pisano's Book of Calculation. First soft edition. New York: Springer.

Siler, S. A., Klahr, D. \& Price, N. (2013). Investigating the mechanisms of learning from a constrained preparation for future learning activity. Instructional Science, 41(1), $191-216$.

Singmaster, D. (2004). Sources in recreational mathematics. An annotated bibliography. Eight preliminary edition. Available at http://puzzlemuseum.com/singma/singma6/SOURCES/singma-sources-edn8-2004-0319.htm\#Toc69534276

Slisko, J. (2010). "Total force" on bodies immersed in air and water: An error living three centuries in physics textbooks. Review of Science, Mathematics and ICT Education, 4(1), 5-23.

Slisko, J. (2011). Repeated errors in physics textbooks: What do they say about the culture of teaching? In Raine, D., Hurkett, C. \& Rogers, L. (Eds.), Physics Community and Cooperation. Vol. 2, Proceedings of the GIREP-EPEC \& PHEC 2009 International Conference, Leicester: Lulu / The Center for Interdisciplinary Science, University of Leicester, 31-46. 
Thacker, B., Kim, E., Trefz, K. \& Lea, S. M. (1994). Comparing problem solving performance of physics students in inquiry-based and traditional introductory physics courses. American Journal of Physics, 62(7), 627-633.

Tural, G., Akdeniz, A. R. \& Alev, N. (2010). Effect of 5E teaching model on student teachers' understanding of weightlessness. Journal of Science Education and Technology, 19(5), 470-488.

Wagner, T. (2008). Rigor redefined. Educational Leadership, 66(2), 20-25.

Wells, D. (2012). Games and mathematics. Subtle connections. New York: Cambridge University Press.

Wells, M., Hestenes, D. \& Swackhamer, G. (1995). A modeling method for high school physics instruction. American Journal of Physics, 63(7), 606-619.

White, R. \& Gunstone, R. (1992). Probing Understanding. London and New York: Falmer Press.

Wieman, C. \& Perkins, K. (2005). Transforming physics education. Physics Today, $58(11), 26-41$.

Wilson, J. M. (1994). The CUPLE physics studio. The Physics Teacher, 32(9), 518-523.

Zimmerman, B. J. (1990). Self-regulated learning and academic achievement: An overview. Educational psychologist, 25(1), 3-17.

Zimmerman, B. J. (2002). Becoming a self-regulated learner: An overview. Theory into practice, 41(2), 64-67.

Zimmerman, B. J. \& Schunk, D. H. (Eds.). (2013). Self-regulated learning and academic achievement: Theoretical perspectives. New York: Routledge.

JosIP SLIŠKO

Benemérita Universidad Autónoma de Puebla, Puebla, Mexico 